\title{
Recuperar la política desde la deliberación
}

\author{
Quim Brugué \\ Universitat Autònoma de Barcelona \\ Quim.Brugue@uab.cat
}

Resumen: La política se encuentra actualmente en una encrucijada: vive en una situación de creciente descrédito $y$, simultáneamente, de una imprescindible necesidad. En un mundo cada vez más complejo y diverso, la política es aquello que debe permitirnos vivir juntos sin que explosionen nuestras diferencias. Abora bien, para recuperar la política el autor se propone profundizar en la dimensión deliberativa de la democracia. En este sentido, el artículo define las bases conceptuales y operativas de la democracia deliberativa en tanto que pilares sobre los cuales abordar la recuperación de la política.

Palabras clave: política, democracia, deliberación, participación.

Abstract: Politics is in difficulties. It is constantly blamed by people, who also require it to respond. The world is increasingly complex and diverse, and politics is needed to facilitate the continuity of a civilized community. The article defines the conceptual and operative bases of deliberative democracy, which is interpreted as the way to restore faith in politics.

Keywords: politics, democracy, deliberation, participation. 


\section{Necesitamos política, una nueva política}

Es un lugar común hablar del descrédito de la política. Se trata de un diagnóstico tan compartido que sólo parece preocuparnos retóricamente, como un penoso ejercicio de reconocimiento de una realidad ante la cual no sabemos cómo reaccionar. El debilitamiento de la política no es, sin embargo, una noticia irrelevante. Cuando la política no es capaz de realizar adecuadamente su trabajo no provoca únicamente el desprestigio de los profesionales que trabajan en ella, sino también, y esto es más grave, se pone en peligro algo tan fundamental como nuestra propia capacidad para resolver los problemas colectivos.

Sin política no somos capaces de construir nada en común, ni tampoco de abordar los conflictos que, inevitablemente, entrecruzan nuestras sociedades. Siempre hemos necesitado la política para poder vivir juntos siendo diferentes, aunque hoy esta necesidad es especialmente acuciante. Nos encontramos con la paradoja de una creciente complejidad social (cada vez somos más diferentes, más diversos, más plurales) y, al mismo tiempo, una creciente renuncia a aquello que ha de permitirnos vivir juntos; es decir, a la política.

De entrada, parece bastante claro que buena parte del descrédito de la política tiene que ver con lo que podríamos llamar su actual impotencia. Parafraseando la conocida metáfora de Zygmunt Bauman (2000), en el actual mundo líquido la política bace aguas. La política se encuentra hoy desbordada por unos asuntos que ya no están en sus manos, que escapan a sus posibilidades de forma parecida a cómo se escurre el agua cuando pretendemos retenerla en nuestras manos desnudas. La actual agenda política nos remite a la preocupación frente a los flujos migratorios, a la necesidad de hacer frente al cambio climático, a los miedos que despierta el terrorismo global o al control de las deslocalizaciones empresariales y a la gestión de sus impactos laborales. Todos estos asuntos son los que hoy nos interesan, mientras que las mesas de nuestros políticos son demasiado estrechas para contenerlos.

Esta impotencia tiene diversos orígenes. Quizá uno de los más citados hace referencia al hecho de que mientras la economía, la ecología o la demografía se han hecho globales, la política sigue siendo estatal; es decir, continúa territorialmente confinada. La política es sólida en un mundo líquido, nos diría Bauman (2000). La política, usando ahora los términos de Beck (1998), ha perdido su poder porque éste reside hoy en la capacidad de irse, de moverse de un sitio a otro sin ataduras. Aquí reside el poder de las corporaciones multinacionales; en su capacidad para escaparse y evitar cualquier compromiso local. Y aquí encontramos la debilidad de la política; anclada territorialmente, inmovilizada por una tupida red de compromisos y condenada a responder localmente a aquello que se 
le plantea globalmente. La política no sería, así pues, la causa sino la víctima de una situación que la condena a la impotencia, al fracaso, al descrédito.

Esta situación nos demuestra el desajuste existente entre la explosiva emergencia de una nueva sociedad y el pertinaz estancamiento en la vieja política (Subirats, 2003; Font, 2001). Nuestra sociedad es cada vez más compleja, como también lo son sus retos y sus problemas; pero nuestra política es cada vez más vieja, más incapaz de entender y gestionar una realidad que la desborda.

\section{La debilidad de la política}

No vamos a entrar en una genealogía de la política, ya que únicamente nos interesa recordar su acepción más obvia e intuitiva. La política existe porque existen conflictos entre intereses $y$ visiones alternativas, y porque necesitamos - a pesar de nuestras diferencias - vivir juntos. Ante las dificultades que surgen de esta paradoja - estar juntos siendo diferentes-, la política nos proporciona un espacio público en el que construir civilizadamente nuestros proyectos colectivos.

Pero la política no es sólo la forma de resolver nuestros conflictos presentes, sino también el medio para dar forma a nuestro futuro -imaginándolo, transformándolo, creándolo. La política es, así pues, un ingrediente fundamental para la convivencia, pero para que pueda actuar requiere un espacio público en el que poder encontrarnos, debatir y tomar decisiones vinculantes para la colectividad. Hoy, como ya hemos anticipado, la política se encuentra impotente ante un mundo globalizado y acelerado; ante un entorno en donde el empuje individualista ha arrinconado el espacio público, en donde el diálogo se ha convertido en una pasarela de monólogos y en donde, en definitiva, nos sentimos poco interesados en aquellas decisiones, en aquellos proyectos que por ser de todos nadie parece asumir como propios. La política da hoy muestras de debilidad, al mismo tiempo que esta debilidad afecta inevitablemente a nuestro modelo de convivencia.

El profesor Zygmunt Barman nos habla, en esta dirección, de la existencia de un espacio público «vaciado de contenido». Un espacio público que languidece y que en su imparable proceso de desaparición destruye la política y aquello que la hace más imprescindible, es decir, la capacidad para pensar e imaginar la sociedad. Sin esta capacidad para vislumbrar un proyecto colectivo se impone el discurso individualista y la impotencia de la política como fuerza reguladora y transformadora de la sociedad (Bauman, 2001). En un mundo crecientemente individualizado ya no se trata de construir comunidades (el futuro de todos) sino de diseñar biografías (el presente de cada uno); no pretendemos incidir en nuestro entorno (estrategia transformadora) sino que nos limitamos a preocuparnos 
por cómo nos movemos en él (estrategia adaptativa). Sin proyecto colectivo estar juntos no tiene sentido, se convierte en una pérdida de tiempo. No nos interesa conversar civilizadamente para dar cauce a nuestros desacuerdos, sino espabilarnos individualmente para dar salida a nuestras ambiciones.

Así pues, sin política no existe proyecto colectivo y se impone la lógica de un individualismo radical de raíces liberales. Pero sin proyecto colectivo se impone también una realidad menos sugerente; se impone la soledad de las preocupaciones privadas $y$, consecuentemente, el miedo que provoca la necesidad de hacer frente al mundo con los generalmente escasos recursos de cada uno. El individualismo nos convierte en David y nos enfrenta a Goliat y, por lo tanto, es lógico que tengamos miedo:

En tal situación hay [...] un miedo continuo que amenaza de muerte violenta; y la vida del hombre es solitaria, pobre, triste, brutal y corta. (Hobbes, 1965).

La libertad y el miedo son, así pues, las dos caras de una misma moneda. La visión liberal de la naturaleza humana otorga protagonismo al individuo, pero le resta complejidad; asume su disposición para la lucha en pro del propio interés, pero le priva de todo potencial para la colaboración, la solidaridad y el compromiso colectivo (Cortina, 1997). Los individuos han sido creados para la libertad, pero pagan el precio de una lucha constante $y$, para muchos, aterradora. Su libertad sacrifica la política, aquel límite que podría ofrecer cierta protección y seguridad ante la amenaza de la propia libertad. Los hombres — usando la expresión de Benjamín Barber (2004: 157) — son Dioses o bestias, pero jamás ciudadanos. Para ser ciudadanos debemos reconocer la política, creer en ella, y esto no es algo que los liberales estén dispuestos a aceptar.

\section{Recuperar la política y el diálogo, un camino de difícil transcurrir}

Como ya hemos mencionado, son muchos - o, al menos, eso creemos- los que han comprendido la necesidad de recuperar la política y de modificar las formas de gobernar los asuntos públicos. Continuamos, no obstante, enormemente desconcertados sobre cómo materializar nuestras intenciones. Entendemos que la complejidad y la diversidad de nuestras sociedades reclaman maneras también más complejas de regularla y gestionarla, aunque no sabemos muy bien cómo ponernos manos a la obra. 
Hemos elaborado teorías y hemos incorporado multitud de nuevos términos para exponerlas: gobernanza, posburocracia, nueva gestión pública o, por citar un término más, racionalidad deliberativa (Barzelay, 1992; Hammer y Champy, 1993; Heckscher y Donnellon, 1994; Kickert et alii, 1997; Kooiman, 1993 y 2003; Agranoff y McGuire, 2003). Pero nos hemos quedado sin palabras a la hora de concretar.

Empezar por las dificultades puede parecer un mal comienzo, pero pensamos que resulta imprescindible. Hablar de nueva política supone referirse a una oportunidad, pero eso no significa que sea fácil. Empezar siendo conscientes de las dificultades es, así pues, una necesidad si no queremos limitarnos a hablar de quimeras. En un intento de simplificar, podemos identificar tres grandes tipos de dificultades, cada una de un alcance y una dimensión diferente, aunque todas ellas hacen referencia a cuestiones de amplio espectro.

\subsection{Dificultades culturales}

Aunque con el objetivo de recuperar la política proclamemos la bondad del diálogo y la deliberación como una nueva forma de adoptar decisiones y de ejecutarlas, lo cierto es que a menudo nuestros genes - culturalmente condicionados- no opinan del mismo modo. Nuestra sociedad, desde la Ilustración, ha venerado la racionalidad y el conocimiento científico como las fuentes más fiables para saber qué tenemos que hacer y cómo tenemos que hacerlo. Podemos entender discursos y conceptos más o menos novedosos, pero su capacidad para desmontar nuestra confianza tecnocrática, secularmente construida, no es tan inmediata. Jürgen Habermas puede estar más de moda que Max Weber, pero esto no significa que la sociedad haya interiorizado la sustitución de la racionalidad tecnocrática por la racionalidad deliberativa (Habermas, 1999; Gutmann y Thompson, 1996).

\subsection{Dificultades políticas}

El cambio cultural es muy difícil, entre otras razones porque el entorno político tampoco lo favorece. La política actual, llevada en voladas por la presión y la centralidad de los medios de comunicación, se ha volcado al mundo del espectáculo, donde lo único que cuenta es la frase corta, el mensaje llamativo o el ataque al adversario. Los políticos y los medios de comunicación forman una extraña pareja, y en su tortuosa relación están despojando a la política de pedagogía, están eliminando su capacidad de argumentar y, en definitiva, están transformando aquello 
que debería ser una forma civilizada de abordar los conflictos en un escenario para la exhibición y el griterío (Sampedro, 2003).

La política debería ser debate, pero se ha convertido en monólogo, en eslóganes que no pretenden explicar nada ni convencer a nadie. Su único objetivo es ser proclamados en voz alta. La política debería representar el sofisticado arte de la persuasión, del discurso, del enfrentamiento dialéctico y de la búsqueda de conclusiones de síntesis. Sin embargo, hoy la política no parece estar para florituras: la política tiende a la banalización, mientras que la mayoría de los políticos se limitan a mercadear mensajes con unos medios a los que, ya sin pudor, únicamente les interesa vender más o conseguir más audiencia (Innerarity, 2006; Manin, 1997).

\subsection{Dificultades sociales}

Frente a las dificultades culturales y políticas, las dinámicas sociales tampoco nos ofrecen un panorama demasiado alentador. La ciudadanía se ve hoy impregnada por un intenso proceso de individualización. Aquella vieja idea según la cual «la unión hace la fuerza» se percibe como una obsoleta ridiculez, al tiempo que se consolida un imperativo «espabílate». Hemos de ser emprendedores en nuestros proyectos, tanto profesionales como personales, de manera que los otros son vistos como competidores y el contexto en el que nos movemos no es más que un mercado. El individualismo rampante nos aleja de cualquier proyecto colectivo (Sennet, 2000).

El espacio público, en consecuencia, ya no es el lugar donde, a través del diálogo, convertimos los intereses privados en intereses colectivos, sino un escenario donde se vocean en público los intereses privados. Los ciudadanos estamos demasiado preocupados por nuestros propios proyectos para ocuparnos de aquellos que son de todos. No pretendemos construir una sociedad, sino que nos concentramos en nuestros asuntos personales. Estamos, de hecho, abdicando de nuestra condición de ciudadanos y, según parece, preferimos ser consumidores. Hemos sustituido definitivamente el ágora por el centro comercial (Bauman, 2001).

Pese al alcance de las dificultades descritas, la realidad nos está presionando para que encontremos respuestas. Tenemos una política debilitada, pero necesitamos fortalecerla para recuperar su capacidad de construcción colectiva. El reto es extraordinario y no existen soluciones simples. Creemos, sin embargo, que la apuesta por una democracia deliberativa nos sitúa en la senda correcta. Una senda que nos ha de permitir superar los límites de la democracia liberal y explotar los potenciales de su alternativa deliberativa. 


\section{Los límites de la democracia liberal y el potencial de la democracia fuerte}

La democracia es, desde nuestro punto de vista, el lugar donde hemos de buscar la solución. Mucho se ha debatido sobre su significado y sus formas, a menudo olvidando que la pregunta crucial a la que debe responder es clara y simple: ¿cómo lograr que los ciudadanos resuelvan unos desacuerdos que son endémicos a la propia vida social? La democracia no debería limitarse a escoger a los ganadores (aunque ésta sea la versión liberal de la democracia como agregación) sino que debería generar modelos de convivencia (facilitar que los legítimamente diferentes puedan compartir un proyecto común). Es, así pues, en el proceso democrático donde hemos de recuperar la capacidad para construir una nueva política adecuada para la nueva sociedad.

Sin embargo, las democracias occidentales han sido, incluso desde el punto de vista conceptual, formas políticas muy vulnerables. Se las ubica en la periferia de unas teorías liberales preocupadas sobre todo por la defensa del interés privado y de la propiedad, lo cual las convierte en algo aceptado como inevitable pero deseado con poco entusiasmo. Las aproximaciones liberales han generado, en palabras de Benjamin Barber, una «teoría blanda de la democracia». Una teoría basada en la desconfianza sobre la propia capacidad de las criaturas humanas para relacionarse y construir proyectos compartidos. Una política convencida de la incapacidad fundamental de la bestia bumana para vivir conjuntamente con otras bestias humanas y, por lo tanto, de la imposibilidad de congregar a los ciudadanos en comunidades.

En este contexto, la democracia no es capaz de crear nada colectivo. La democracia blanda de los liberales puede reflejar los intereses estáticos de las bestias e, incluso, desplegar formulas para agregarlos; pero nunca podrá juntarlas para, de este modo, propiciar una política creadora y transformadora. La política liberal no cree en las personas y, por lo tanto, tampoco puede creer en la democracia. En el mejor de los casos la acepta como un mal menor.

Frente a la perspectiva liberal, la tradición republicana considera que el proceso democrático no desarrolla una simple función mediadora entre intereses individuales, sino que, usando los términos de Habermas (1999), constituye el medio a través del cual los miembros de una comunidad, con cierto sentido de solidaridad, asumen su dependencia recíproca y establecen relaciones de reconocimiento mutuo. La política no es un mal necesario, sino un entramado ético donde se conforman asociaciones y voluntades colectivas. Porque los humanos somos algo más que bestias interesadas; somos también seres contradictorios, 
complejos, ambivalentes. No estamos condenados a vivir en jaulas, sino que podemos convertirnos en ciudadanos y recorrer las calles sin abalanzarnos los unos sobre los otros.

El ciudadano liberal es, usando términos más precisos, alguien que ostenta derechos subjetivos frente a los otros y, de esta manera, puede dedicarse a la persecución de sus propios intereses - dentro de los límites de la ley y contando con la protección del Estado. El ciudadano republicano, por su parte, no se define a través de una lista de derechos subjetivos y libertades negativas, sino de derechos civiles y libertades positivas. No se trata únicamente de asegurar su propia libertad frente a eventuales coacciones externas, sino de vehicular su participación en una práctica y un proyecto común. Nos trasladamos, así, a lo que el propio Barber ha conceptualizado como una «versión fuerte de la democracia». La democracia fuerte no se presenta como una simple agregación y equilibrio entre intereses, sino que descansa sobre la idea de una comunidad autogobernada de ciudadanos.

Frente a la política del regateo y el intercambio de la democracia blanda, la versión fuerte se sustenta en una política entendida como transformación. De este modo, la democracia fuerte no aborda el conflicto como un problema, sino como una oportunidad para cooperar en un proceso de transformación colectiva. En su centro no está, así pues, un método para agregar intereses individuales y, de este modo, despolitizar los problemas, sino la secuencia deliberación-decisiónacción, entendida como la formación de un ágora en donde los desacuerdos particulares se convierten en proyectos públicos. La democracia fuerte, de esta manera, convierte a la manada de fieras en una comunidad de ciudadanos habilitados para participar en la construcción de su destino compartido.

\section{Una apuesta por recuperar la política a través del diálogo: democracia deliberativa}

De la secuencia que define la democracia fuerte nos interesa centrarnos en la primera fase; es decir, en la deliberación o el diálogo. Otorgar un papel de centralidad al diálogo supone recuperar aquel viejo principio según el cual el todo es más que la suma de las partes. El debate no se limita a un intercambio pasivo sino que se convierte en una construcción activa. De esta manera, el espacio público no es simplemente el lugar en donde emerge un resultado agregado, sino donde se construye un proyecto de vida en común. En un modelo de democracia republicana los ciudadanos no son meros defensores de sus propuestas, sino que convencen y son convencidos, se comunican y argumentan para madurar jun- 
tos nuevas opiniones. Es entonces cuando el diálogo se dota de valor, cuando la política puede sorprendernos y ser creativa, y cuando se engarza el concepto de democracia deliberativa (Cohen, 1989; Fishkin, 1991 y 1995; Pettit, 1997; Habemas, 1999; Gutman y Thomson, 2004).

La democracia deliberativa constituye una aportación teórica al debate sobre el funcionamiento de las democracias. No pretende, sin embargo, ser una metateoría, sino una aproximación de segundo nivel, con capacidad para responder a los interrogantes que suscita el actual funcionamiento de los sistemas políticos democráticos. En realidad, la democracia deliberativa hace referencia a un procedimiento de toma de decisiones, a los principios que lo inspiran y a las características que debería tener.

Martí (2006), por ejemplo, nos recuerda la existencia de tres principios básicos en los procesos de decisión: el principio del voto, el principio de la negociación y el principio de la argumentación. El primero es característico de las «democracias de mercado», ya que se basa en las expresiones de preferencias de los individuos y en su agregación a través de determinadas reglas de mayoría (Schumpeter, 1942; Downs, 1956). Por su parte, el principio de la negociación se utiliza de manera preferente en las llamadas «democracias pluralistas» (Dahl, 1956 y 1989). La dinámica de este modelo sigue, como en el caso anterior, basándose en las preferencias interesadas de cada una de las partes, aunque ahora se propone una forma de consenso por acomodación que debería alcanzarse a través de la comunicación, la interacción y el uso del poder de cada uno. El principio de la argumentación sería, claro está, el que se aplicaría de manera distintiva en una «democracia deliberativa». Ahora partiríamos de preferencias imparciales y se pretendería alcanza el consenso a través del intercambio de razones (Bohman y William, 1997; Elster, 1998; Macedo, 1999; Dryzek, 2000; Estlund, 2002).

Algunas de las aportaciones más influyentes a este debate son las que han realizado Gutmann y Thompson (1996 y 2004), cuyos planteamientos vamos a usar para construir los conceptos y el marco de análisis que encuadran las prácticas de la democracia deliberativa.

\section{Democracia deliberativa: ¿de qué estamos hablando?}

Ya nos hemos referido a la democracia deliberativa como un proceso de toma de decisiones basado en el principio de la argumentación. Ahora nos gustaría precisar esta idea inicial a partir de los cinco puntos que Gutmann y Thompson nos proponen para articular una definición operativa de democracia deliberativa: 
i. En primer lugar, en una democracia deliberativa las decisiones, para justificarse, han de ser razonadas. La deliberación supone un intercambio de razones y argumentos. Éstas deben expresarse desde el respeto mutuo y tienen como objetivo construir espacios de cooperación.

ii. En segundo lugar, el intercambio de razones ha de ser comprensible y accesible a los ciudadanos. Es decir, la deliberación debe ser pública en el doble sentido de producirse en un espacio público y de ser comprensible para la ciudadanía.

iii. En tercer lugar, las decisiones que se derivan de un proceso deliberativo deben ser vinculantes, aunque sólo durante un cierto período de tiempo. La deliberación no es una charla informal, sino un proceso que debe generar decisiones concretas. $\mathrm{Al}$ mismo tiempo, estas decisiones son siempre revisables en una deliberación posterior.

iv. El proceso deliberativo, en cuarto lugar, es siempre dinámico. Tal como ya se afirmaba en el punto anterior, el debate debe cerrarse para generar conclusiones concretas, aunque puede abrirse en otro momento para su revisión. Esta permanente provisionalidad se justifica tanto por el hecho de que las decisiones son siempre imperfectas como por la necesidad de renovar de forma continuada los acuerdos políticos.

v. Finalmente, la deliberación se rige por el principio de la economía moral del desacuerdo. Se trata, durante el proceso de intercambio de razones, de maximizar el respeto mutuo y de minimizar las diferencias. El desacuerdo se acepta, aunque se prioriza la voluntad de trabajar juntos y buscar espacios de acuerdo y cooperación.

Así pues, para estos autores la democracia deliberativa define una forma de gobernar en la cual ciudadanos libres e iguales (y sus representantes) se incorporan a un proceso de intercambio de razones y argumentos que se realiza de forma pública y comprensible, y que sirve para justificar unas decisiones concretas; las cuales, sin embargo, pueden volver a revisarse en el futuro. Todo ello desde el respeto y siguiendo el principio de la economía de los desacuerdos morales.

\section{Democracia deliberativa: ¿qué podemos esperar de ella?}

El concepto de democracia deliberativa, volvemos a insistir en ello, es especialmente interesante ante la necesidad de construir una nueva forma de gobernar, 
ya que su objetivo es ofrecernos una manera de tratar adecuadamente con el desacuerdo y la complejidad.

Así pues, de la democracia deliberativa debemos esperar que sea capaz de generar «mejores» políticas, tanto en relación a sus contenidos sustantivos como a la eficiencia en sus formas de desplegarse. Estas mejoras son fundamentales para que la democracia deliberativa sea capaz de dar respuesta a algunos de los principales retos que tiene planteada la construcción de una nueva política. En concreto, recuperando el esquema propuesto por Gutmann y Thompson (2004), esperaríamos que esta nueva forma de gobernar y de hacer frente a los retos complejos que nos plantea el mundo actual pudiera dar cuenta de cuatro grandes retos:

i. En primer lugar, dado que los recursos son escasos y nos obligan a tomar decisiones delicadas, la democracia deliberativa debería incrementar la legitimidad de las decisiones colectivas.

ii. En segundo lugar, dado que nuestra generosidad es limitada, la democracia deliberativa debería favorecer una perspectiva pública en asuntos de interés colectivo.

iii. En tercer lugar, dada la inevitable incompatibilidad entre valores morales, la democracia deliberativa debería reconocer las virtudes de cada posición y estimular el respeto mutuo a la hora de tomar decisiones.

iv. Finalmente, dada la incapacidad de un conocimiento completo en un mundo tan poliédrico y complejo, la democracia deliberativa debería ayudar a reconocer errores y limitaciones, al tiempo que promueve el aprendizaje y una mayor comprensión de la realidad.

Valorar los procesos de participación en términos de resultados resulta fundamental, entre otras razones porque nos ayuda a conjurar la tentación endogámica de algunos de estos procesos. Es evidente que éstos deben satisfacer determinados requisitos de calidad procedimental; pero también es cierto que no debemos desarrollar experiencias de democracia deliberativa únicamente pensando en la calidad — cuando no en la vistosidad — del propio proceso. Nos interesan sobre todo desde la óptica del «para qué»; es decir, en la medida en que contribuyen a satisfacer determinados resultados y a producir determinados impactos. El análisis de estos resultados e impactos es complejo, ya que requiere medidas cualitativas más difíciles de obtener. Sin embargo, sin ellos estaríamos olvidándonos no sólo de nuestra hipótesis de trabajo sino también de la propia razón de ser del debate en torno a la democracia deliberativa. 


\section{Democracia deliberativa: ¿cómo desplegarla?}

Aunque la prioridad de un proceso deliberativo se encuentre en sus resultados, sus características procedimentales son también cruciales, ya que de ellas depende precisamente la capacidad para alcanzar mejores o peores resultados. En este sentido, la mayoría de la literatura, usando unos u otros términos, coincide en reconocer que a la hora de desplegar un proceso deliberativo hay que tomar en consideración tanto las características formales del proceso como las actitudes y los valores que lo impregnan.

\subsection{Las características externas (formales) del proceso deliberativo: pautas de funcionamiento}

Un proceso de deliberación es un diálogo constructivo: un proceso durante el cual se intercambian argumentos y razones con el objetivo de tomar una decisión concreta. En una deliberación, la decisión no puede estar tomada de antemano; pero tampoco se puede debatir y debatir sin alcanzar un resultado claro y tangible. Como nos recuerdan Fox y Miller (1995), se trata de organizar un diálogo que evite tanto el monólogo (una ficción discursiva en la que la decisión está en manos de unos pocos) como el chismorreo (una charla informal y solapada donde no es necesario alcanzar ningún resultado operativo concreto).

Articular un diálogo constructivo en el que se produzca tanto un intercambio franco y abierto de razones y de posiciones como un resultado concreto en términos de decisión no resulta tarea fácil. Para lograrlo - desde una óptica operativa - se deben satisfacer como mínimo tres momentos imprescindibles para articular cualquier diálogo constructivo: (1) explicarnos (clarificar y comunicar los contenidos y los objetivos del debate), (2) escuchar a la ciudadanía (invitándola a espacios de debate en donde expresarse de manera clara y ordenada) y (3) responder (dar cuenta de las aportaciones recibidas y de cómo éstas se han trasladado a una decisión concreta, visualizando hasta qué punto las diversas posiciones se han incorporado o no).

Explicarse. El punto de arranque de cualquier diálogo resulta crucial para su posterior desarrollo. Únicamente se podrá desplegar un proceso deliberativo con garantías si previamente se ha clarificado sobre qué se quiere deliberar y se ha dado suficiente difusión al proceso. Se trata, así pues, de una tarea pedagógica y comunicativa inicial sin la cual será imposible que el posterior debate se pueda producir de manera adecuada. La información y la comunicación no son partici- 
pación ni deliberación, pero sin ellas cualquier proceso participativo y/o deliberativo está condenado al fracaso.

Además, y redundando en la misma idea, la calidad del proceso deliberativo dependerá de la calidad inicial de las estrategias de información y comunicación. La información debe ser clara, honesta y adaptada en el lenguaje y el formato para hacerla comprensiva a las poblaciones receptoras. De forma parecida, la comunicación deberá estar planificada, ser pedagógica y usar canales diversificados para alcanzar a todos los ciudadanos y/o actores que deberían participar en el proceso.

Escuchar. En una segunda fase se trata de organizar y dinamizar los espacios de debate a través de los cuales se produce el intercambio de razones y se canalizan sus aportaciones a la toma de decisiones. En este momento resulta crucial responder adecuadamente a dos preguntas básicas: ¿quién ha participado en el proceso deliberativo y cómo se ha desarrollado este proceso?

Respecto al quién, deberemos incorporar varios criterios: la extensión (¿`cuántos han participado?), la intensidad (¿en qué medida se han involucrado en el proceso?), la representatividad (¿hemos llegados a las voces que hablan legítimamente en nombre de determinadas visiones o posiciones?) y la diversidad (¿están todas las voces que deberían estar o tenemos una participación sesgada?). Al usar criterios múltiples estamos, de hecho, aceptando la necesidad de un equilibrio entre los mismos. Es decir, no podemos únicamente obsesionarnos por aumentar el número de participantes o por someterlos a eventuales exámenes acreditativos de su representatividad. Debemos, en cambio, buscar un equilibrio razonable que, dadas las características de cada proceso deliberativo, nos permita valorar el quién de la participación en función de su número, su diversidad, su representatividad y la intensidad de su participación.

En relación al cómo, el proceso deliberativo debe estar, en primer lugar, organizado a través de unas reglas claras, conocidas y pactadas anticipadamente (al menos con los actores más relevantes). En segundo lugar, estas reglas deben desarrollarse con la máxima profesionalidad; garantizando la calidad de los materiales y los espacios utilizados, la efectividad de la dinamización, la adecuación de las convocatorias y los calendarios de trabajo, etc. A menudo se considera que la organización de un proceso deliberativo es una actividad banal y se descuidan estos aspectos. Los resultados pueden ser desastrosos ya que, si bien es cierto que no se trata de procesos tecnológicamente complejos, sí que son muy sensibles y fácilmente pueden desmotivar o frustrar las expectativas de los participantes. Es, pues, fundamental tratar el cómo con una gran sensibilidad, prestando mucha atención a los detalles y cuidando todos aquellos aspectos que facilitan el proceso 
de interacción de las partes. Las metodologías a utilizar son diversas, pero en todos los casos se debe mantener esta tensión en pro de la profesionalidad y la calidad del proceso.

Responder. Finalmente, los diálogos, para ser constructivos, han de producir resultados concretos y, a la vez, han de rendir cuentas de estos mismos resultados. Es decir, en primer lugar, el proceso debe generar unas conclusiones claras, que deben ser «devueltas» a los participantes en el proceso deliberativo; es decir, los participantes deben conocer y validar cómo su participación ha generado unos resultados concretos. Estos resultados, obviamente, pueden expresarse tanto en términos de acuerdos como de desacuerdos, aunque siempre siguiendo el criterio - al que nos referiremos a continuación - del respeto mutuo.

Por otra parte, en segundo lugar, los participantes tienen que poder evaluar no únicamente como se han recogido sus deliberaciones sino también hasta qué punto los contenidos de las mismas han sido incorporados y, por lo tanto, en qué medida han influido en la decisión final. Únicamente si se articula y se visualiza con claridad esta tercera fase podremos evaluar los impactos reales del proceso deliberativo. $\mathrm{Al}$ mismo tiempo, únicamente estos impactos reales acabaran justificando la necesidad y la oportunidad del propio proceso.

\subsection{Las características internas (actitudes y valores) del pro- ceso deliberativo¥ pautas de comportamiento}

Los procesos deliberativos, además de asegurar el adecuado desarrollo de las características externas que hemos repasado en el punto anterior, deben abordar los conflictos morales y políticos que definen cualquier proceso deliberativo desde unas actitudes y unos valores determinados. La deliberación, usando un símil deportivo, requiere que los participantes no dispongan únicamente de un terreno de juego en buenas condiciones (en donde intercambiar sus razones), sino que además reclama que los jugadores se comporten siguiendo cierto fair play, obedeciendo determinadas reglas no escritas que regulan sus relaciones y los valores que las rigen.

Una vez reconocida la importancia de las actitudes y los valores, el interrogante que nos aparece es el siguiente: ‘a través de qué principios de conducta (actitudes y valores) deben abordar los ciudadanos sus desacuerdos respecto a una política pública? Ante esta pregunta, la respuesta liberal es sobradamente conocida: se basa en su esperanza de que, como mínimo, los ciudadanos serán capaces de acordar cuáles son las decisiones que no es necesario tratar desde la agenda política. Invocando principios robustos como la neutralidad o la impar- 
cialidad, los liberales aspiran a alcanzar un consenso de base que sirva para aislar el proceso político respecto los molestos conflictos morales.

Desde la perspectiva deliberativa, en cambio, la invocación del consenso que puedan despertar estos principios robustos (de primer orden) no es suficiente para eliminar el conflicto moral; el cual, consecuentemente, no puede ser simplemente expulsado del proceso político. En este sentido, Gutmann y Thompson (2004) invocan el «principio de acomodación». A través de este principio se pretende definir cómo conducir aquellos desacuerdos morales que sí alcanzan la agenda política. Así, cuando buscamos principios para el consenso político en situaciones de desacuerdo moral fundamental, es necesario no valorar únicamente la naturaleza de las diversas posiciones, sino también la manera en que cada persona expresa y defiende sus posiciones. De este modo, el principio de acomodación pretende garantizar que las diferentes posiciones moralmente respetables se expresen de maneras también moralmente respetables. Se trata, en otros términos, de acordar las formas de establecer y dilucidar los desacuerdos.

El principio de acomodación pretende garantizar estas actitudes y estos valores, conducir las relaciones entre ciudadanos que mantienen, desde argumentos morales legítimos, posiciones contradictorias respecto determinadas políticas públicas. Se trata de promover determinada forma de tratar con los adversarios, de acordar las formas del desacuerdo, de evitar que posiciones moralmente respetables sean defendidas a través de formas no respetables. Para lograr estos objetivos, la teoría deliberativa ha situado el criterio del «respeto mutuo» en el centro de las actitudes desde las cuales abordar los desacuerdos.

El respeto mutuo define, desde esta perspectiva, un tipo de carácter democrático. Estamos ante un valor que va más allá de la tolerancia, ya que no únicamente reclama una aceptación pasiva sino una actitud favorable y una interacción constructiva con aquellos con los que se mantiene en desacuerdo. No sólo se toleran las diferencias, sino que se abre la puerta a posibles cambios en las posiciones que cada uno expresa y defiende. Es decir, se trata de un carácter democrático específico que nos insta tanto a ponernos en la piel del otro como a comprometernos a construir algo de manera conjunta. Sólo cuando se mantiene abierta la posibilidad de cooperar de forma constructiva es posible abordar políticamente disputas morales.

El principio de acomodación y la condición del respeto mutuo definen formas de actuar, actitudes de los participantes en un proceso político que hace frente a legítimos conflictos entre visiones alternativas. En una deliberación, por lo tanto, los participantes deben actuar según determinadas leyes no escritas que les obligan a escuchar a los demás y no únicamente a expresar sus posiciones; a mantener un 
tono de respeto en el intercambio de razones y argumentos, a intentar ponerse en el lugar del otro para comprender mejor su posición, a mantener abierta la posibilidad de modificar las propias posiciones si los argumentos son suficientemente convincentes $y$, en definitiva, a demostrar activamente una voluntad de cooperar y alcanzar acuerdos con los demás.

En este sentido, y en contraste con las posiciones liberales, la tradición deliberativa confía en las personas $y$, consecuentemente, otorga una gran importancia a las «virtudes cívicas» de los ciudadanos. Las personas libres pueden ser cívicamente virtuosas y, de este modo, defender democráticamente su propia libertad. Desde esta óptica, la libertad no significa ausencia de interferencias (como para los liberales) sino ausencia de dominación o dependencia (Pettit, 1997). La libertad personal conecta así con la idea de autonomía y con las prácticas de autogobierno. Se trata, en definitiva, de una libertad que se ejerce desde la participación en los asuntos públicos y que, por lo tanto, reclama que todos los ciudadanos estén en igualdad de condiciones en cuanto a sus capacidades de influencia política. El ciudadano virtuoso ostenta el derecho a la libertad y a la autonomía, pero también el deber de ocuparse de los asuntos públicos y de comprometerse en el bien común (Ovejero, 2002; Ovejero, Martí y Gargarella, 2004). Sin las actitudes y los valores de este ciudadano virtuoso las deliberaciones no producirán resultados adecuados.

\section{Bibliografía}

Agranoff, R+y McGuire, M. (2003). Collaboration and Public Management. Washington, DC: Georgetown University Press.

Barber, B. (2004). Democracia Fuerte. Madrid: Almuzara.

BARZELAY, M. (1992). Breaking through bureaucracy: a new vision for managing in government. Berkeley: University of California Press.

Bauman, Z. (2000). Liquid Modernity. Cambridge: Polity Press.

Bauman, Z. (2001). En busca de la política. Barcelona: Paidós.

Bauman, Z. (2001b). La sociedad individualizada. Madrid: Cátedra.

Beck, U. (1998). La sociedad del riesgo. Barcelona: Paidós.

Bohman, J. y William, R. (eds.) (1997). Deliberative Democracy. Cambridge: MIT Press.

Bourdieu, P. (1999). La miseria del mundo. Tres Cantos: Akal.

Cohen, J. (1989). «Deliberation and Democratic Legitimacy», en Hamli, A. y Petтit, P. (eds.) The Good Polity. Oxford: Blakwell. 
Cortina, A. (1997). Ciudadanos del mundo: hacia una teoría de la ciudadanía. Madrid: Alianza.

Darl, R. (1956). A Preface to Democratic Theory. Chicago: Chicago University Press.

Darl, R. (1989). Democracy and its Critics. New Haven: Yale University Press.

Downs, A. (1956). An Economic Theory of Democracy. New York: Harper \& Row.

Dryzek, J. (2000). Deliberative Democracy and Beyond. Oxford: Oxford University Press.

Elster, J. (1998). Deliberative Democracy. Cambridge: MIT Press.

Estlund, G. (eds.) (2002). Democracy. Oxford: Blakwell.

Fishrin, J. (1991). Democracy and Deliberation: New Directions for Democratic Reform. New Haven: Yale University.

Fishrin, J. (1995). The Voice of the People: Public Opinion and Democracy. New Haven: Yale University.

Font, J. (ed.) (2001). Ciudadanos y decisiones públicas. Barcelona: Ariel.

Fox, C. y Miller, H. (1995). Postmodern Public Administration. Towards Discourse. Londres: Sages.

Gutmann, A. y Thompson, D. (1996). Democracy and Disagreement. Cambridge: Harvard University Press.

Gutmann, A. y Thompson, D. (2004). Why Deliberative Democracy? Princeton: Princeton University Press.

Habermas, J. (1999). La inclusión del Otro. Barcelona: Paidós.

Hammer, M., y Champy, J. (1993). Reengineering the corporation: A manifesto for business revolution. New York: HarperBusiness.

Heckscher, C. y Donnellon, A. (1994). The Post-bureaucratic organization: New perspectives on organizational change. Thousand Oaks, California: Sage Publications.

Новbes, T. (1965). Antología: del ciudadano y Leviatán. Madrid: Tecnos.

Innerarity, D. (2006). El nuevo espacio público. Madrid: Espasa Calpe.

Kickert, W. et alii (1997). Managing Complex Networks: Strategies for the Public Sector. Londres: Sage.

Kooiman, J. (1993). Modern Governance. Londres: Sage.

Macedo, S. (ed.) (1999). Deliberative Politics. Oxford: Oxford University Press.

Manin, B. (1997). The Principles of Representative Government. Cambridge: Cambridge University Press.

Martí, J. L. (2006). La república deliberativa. Una teoría de la democracia. Barcelona: Marcial Pons. 
Osborne, D. y Gaebler, T. (1994). La reinvención del gobierno. Barcelona: Paidós.

Ovejero, F. (2002). La libertad inhóspita. Modelos bumanos y democracia liberal. Barceona: Paidós.

Ovejero, F; Martí, J. L.y Gargarella, R. (eds.) (2004). Nuevas ideas republicanas. Autogobierno y libertad. Barcelona: Paidós.

Pettit, P. (1997). Republicanism. A theory of Freedom and Government. Oxford: Oxford University Press.

Pierre, J. y Peters, J. (2000). Governance, Politics and the State. Londres: Macmillan.

Sampedro, V. (ed.) (2003). La pantalla de las identidades. Medios de comunicación, políticas y mercados de identidad. Barcelona: Icaria.

Schumpeter, J. A. (1942). Capitalism, Socialism and Democracy. New York: Harper \& Row.

Sennett, R. (2000). La corrosión del carácter. Barcelona: Anagrama.

Subirats, J. (2003). Elementos de nueva política. Barcelona: CCCB. 